\title{
Pengaruh Persekitaran Luaran ke atas Prestasi Perniagaan PKS
}

\author{
Shuhymee Ahmad*, Abdullah Abd Ghani, Rosli Mohd Saad \\ Kolej Perniagaan, Universiti Utara Malaysia, 06010 Sintok, Kedah, Malaysia \\ *Corresponding author: shuhymee@uum.edu.my
}

\begin{abstract}
This paper examines the influence of the external environment on business performance of SMEs in Malaysia. Previous studies have show that there was inconsistent relationship between external environment variables and business performance. Three external environment variables were examined in this study namely dynamic, hostility and munifience. By using simple random sampling technique, a total of 143 SMEs in Malaysia were used as samples in this study. Correlation analysis and multiple regression were used to test the three hypothesis. Results of the analysis showed that the three independent variables, i.e., dynamic, hostility and munifience have positive significant relationships with business performance. It is hoped that the findings from this study can be utilized by the government, entrepreneurs, researchers and other stakeholders in the field of SMEs in Malaysia.
\end{abstract}

Keywords: Business performance; external environment; Small and Medium Enterprises (SMEs)

\begin{abstract}
Abstrak
Kertas kerja ini mengkaji pengaruh persekitaran luaran ke atas prestasi perniagaan firma PKS di Malaysia. Hasil kajian lepas menunjukkan terdapat hubungan yang tidak konsisten antara pembolehubah persekitaran luaran dengan prestasi perniagaan. Tiga pembolehubah persekitaran luaran telah diperiksa dalam kajian ini iaitu dinamik, persaingan sengit dan mesra perniagaan. Sebanyak 143 buah firma PKS di Malaysia telah dijadikan sampel dalam kajian ini yang dipilih secara rawak mudah. Analisis kolerasi dan regresi berganda telah digunakan untuk menjawab tiga hipotesis kajian. Keputusan kajian menunjukkan ketiga-tiga pembolehubah tidak bersandar iaitu dinamik, persaingan sengit dan mesra perniagaan mempunyai hubungan yang signifikan positif dengan prestasi perniagaan. Dapatan dari kajian ini diharap dapat dimanfaatkan oleh pihak kerajaan, usahawan, pengkaji lain, dan pihak-pihak yang berkepentingan dalam bidang PKS di Malaysia.
\end{abstract}

Kata kunci: Prestasi perniagaan; persekitaran luaran; Perusahaan Kecil dan Sederhana (PKS)

(C) 2017 Penerbit UTM Press. All rights reserved

\subsection{PENGENALAN}

Perusahaan Kecil dan Sederhana (PKS) menjadi pemangkin kepada pertumbuhan ekonomi serta memainkan peranan penting dalam program perindustrian sesebuah negara (Normah, 2007). Peranan serta sumbangan PKS dari sudut jumlah pertubuhan perniagaan, peluang pekerjaan dan sumbangan kepada Keluaran Dalam Negara Kasar (KDNK) dalam kalangan negara-negara maju serta negara membangun adalah sangat besar (SME Corp. Malaysia, 2009). Menurut The World Bank (2008), secara keseluruhannya PKS di seluruh dunia telah menyumbang lebih daripada 60 peratus kepada KDNK dan 70 peratus bagi jumlah tenaga kerja di negara-negara berpendapatan per kapita yang rendah (US\$100-US\$500). Manakala sumbangan PKS kepada negara-negara berpendapatan sederhana adalah sebanyak 70 peratus bagi KDNK dan 95 peratus bagi jumlah tenaga kerja. Seterusnya bagi negara-negara berpendapatan tinggi seperti Amerika Syarikat (U.S.) serta negara-negara Eropah, jumlah sumbangan kepada KDNK adalah sebanyak 55 peratus dan menyediakan jumlah tenaga kerja sebanyak 65 peratus (The World Bank, 2008).

Walau bagaimanapun, transformasi persekitaran perniagaan global yang disebabkan oleh krisis ekonomi dan kewangan semasa di negara-negara perindustrian dan tekanan liberalisasi yang berterusan, telah menimbulkan pelbagai masalah serta cabaran baharu kepada semua PKS di dunia dan di Malaysia (SME Corp. Malaysia, 2015). Di samping itu, turun naik harga minyak yang sukar dikawal, krisis makanan sedunia, krisis politik serta bencana alam turut memperlahankan aktiviti perniagaan di seluruh dunia termasuk di Malaysia (SME Corp. Malaysia, 2015; The World Bank, 2015; International Monetary Fund [IMF], 2015). Kaji selidik yang dijalankan oleh SME Corp. Malaysia pada tahun 2015, mendapati PKS di Malaysia telah menerima kesan ketara ke atas perubahan persekitaran perniagaan tersebut (SME Corp. Malaysia, 2016). Disebabkan cabaran serta permasalahan yang dihadapi oleh PKS, maka ramai pengkaji lepas berminat untuk mengkaji PKS terutama dari sudut prestasi perniagaannya (Madrid-Guijarro et al., 2007; Pasanen, 2003) baik di negara maju atau pun negara membangun. Yang (2006) turut mencadangkan agar prestasi PKS sentiasa dipantau dan dikaji disebabkan oleh masalah dan cabaran semasa (Pasanen, 2003; SME Corp. Malaysia, 2014).

Banyak kajian telah dijalankan bagi mengenal pasti faktor-faktor yang boleh mempengaruhi prestasi firma PKS (Pasanen, 2003; Madrid-Guijarro et al., 2007) terutama PKS di Malaysia (Amran, 2006). Rauch et al. (2009), Lumpkin dan Dess (1996) dan Wiklund dan Shepherd (2005) telah mencadangkan pemeriksaan ke atas pengaruh faktor luaran firma yang berkemungkinan turut mempengaruhi prestasi firma PKS. Hasil daripada kajian lepas telah mendapati faktor persekitaran luaran telah mempengaruhi operasi sesebuah firma 
(Azizi, 2010; Dess \& Beard, 1984). Firma keusahawanan yang beroperasi dalam persekitaran yang tidak pasti sentiasa terdedah kepada risiko kegagalan (Azizi, 2010). Oleh itu, kajian berterusan mengenai pengaruh persekitaran perniagaan khususnya persekitaran luaran dinamik, persaingan sengit dan mesra perniagaan ke atas firma keusahawanan perlulah dilakukan bagi melihat kesannya ke atas prestasi perniagaan (Azizi, 2010; Rauch et al., 2009; Davis, 2007; Amran, 2006).

Sehubungan dengan itu, satu kajian secara empirikal mengenai hubungan antara pembolehubah persekitaran luaran (dinamik, persaingan sengit dan mesra perniagaan) dengan prestasi perniagaan perlu dilakukan. Secara spesifiknya, objektif kajian ini adalah untuk menentukan hubungan antara pembolehubah persekitaran luaran dinamik, persaingan sengit dan mesra perniagaan dengan prestasi perniagaan firma PKS di Malaysia.

\subsection{KAJIAN LITERATUR}

Faktor persekitaran perniagaan memainkan peranan utama dalam menentukan kejayaan atau kegagalan firma PKS (Mohd Khairuddin, 2002). Menurut Alkali (2012), persekitaran perniagaan terdiri daripada persekitaran luaran dan dalaman yang akan mempengaruhi serta memberi impak kepada prestasi perniagaan usahawan. Oleh itu, usahawan harus sentiasa memantau serta mengambil tindakan ke atas sebarang perubahan dalam persekitaran luaran. Robbins dan Coulter (2007) telah mengkategorikan persekitaran luaran ini kepada dua komponen iaitu persekitaran khusus yang terdiri daripada ekonomi, sosiobudaya, politik atau undang-undang, demografi, teknologi serta kuasa-kuasa global manakala persekitaran umum melibatkan pelanggan, pembekal, pesaing serta tekanan dari pihak awam. Kesemua kuasa-kuasa ini akan memberi tekanan secara langsung atau tidak langsung kepada firma dan seterusnya akan mempengaruhi prestasi firma (Donaldson, 2001).

Menurut Donaldson (2001), kesan atau impak dari kuasa-kuasa tersebut boleh dikategorikan kepada ciri-ciri dinamik, persaingan sengit (hostility), mesra (munificence) dan kerumitan (complexity) (Dess \& Beard, 1984; Duncan, 1972; Donaldson, 2001). Terdapat kajian lepas yang memeriksa kesan atau impak hubungan langsung antara persekitaran luaran dengan prestasi (Lumpkin, 1996). Oleh yang demikian, berdasarkan kepada hasil dan cadangan daripada kajian lepas, Rauch et al. (2009) telah bersetuju bahawa persekitaran luaran boleh bertindak atau berperanan sebagai pembolehubah kontingensi (Rauch et al., 2009; Davis, 2007; Kreiser et al., 2002) yang mempunyai kesan langsung dengan prestasi perniagaan firma PKS (Amran, 2006).

Sehubungan dengan itu, Davis (2007), Zahra (1993), Lumpkin (1996) dan Lumpkin dan Dess (1996) telah bersetuju yang persekitaran luaran dinamik, persaingan sengit dan mesra adalah antara pembolehubah yang perlu dikaji kerana ketiga-tiganya telah diterima secara meluas sebagai dimensi persekitaran luaran di dalam kebanyakan kajian lepas (Davis 2007). Sehubungan dengan itu, kajian ini hanya akan membincangkan ketiga-tiga pembolehubah persekitaran luaran (dinamik, persaingan sengit dan mesra) berdasarkan kepada cadangan daripada pengkaji lepas seperti yang dibincangkan di atas. Persekitaran luaran ini akan bertindak sebagai pembolehubah tidak bersandar yang mungkin akan memberi kesan kepada prestasi perniagaan.

\subsection{Persekitaran Luaran Dinamik}

Menurut Duncan (1972) dan Dess dan Beard (1984) antara ciri-ciri utama persekitaran dinamik adalah keadaan yang tidak dapat diramal dan kadar perubahan yang pantas menyebabkan wujud elemen ketidakpastian kepada operasi firma dalam sesuatu industri. Manakala Miller dan Friesen (1983) telah mendefinisikan persekitaran dinamik sebagai kadar perubahan dan inovasi dalam sesebuah industri dan juga tahap ketidakpastian atau ketidakjangkaan dari tindakan pesaing dan pelanggan. Kuznik (2006) pula merujuk persekitaran dinamik sebagai berada di dalam keadaan pasaran yang tidak pasti, kerumitan serta perubahan yang memberi kesan kepada firma.

Kajian empirikal yang dilakukan oleh pengkaji lepas seperti kajian Amran (2006), Lumpkin dan Dess (2001) dan Zahra (1993) telah bersetuju di mana firma keusahawanan yang beroperasi di dalam persekitaran dinamik mempunyai hubungan yang positif dengan prestasi perniagaan. Walau bagaimanapun, terdapat juga dapatan dari kajian lepas yang menunjukkan keputusan yang sebaliknya. Contohnya, kajian Kreiser et al. (2002) telah mendapati keputusan yang bercampur-campur. Keputusan kajian tersebut mendapati persekitaran dinamik hanya mampu mempengaruhi hubungan yang positif dengan prestasi untung kasar manakala hubungannya dengan tingkat jualan dan pertumbuhan jualan tidak dapat dibuktikan kerana tidak signifikan. Didapati hasil kajian Davis (2007) turut selari dengan sebahagian daripada kajian Kreiser et al. (2002) yang mendapati persekitaran luaran dinamik tidak mampu mempengaruhi prestasi perniagaan. Sehubungan dengan itu, pengkaji cuba untuk menguji hipotesis berikut;

Hipotesis 1: Persekitaran luaran dinamik mempunyai hubungan yang signifikan dengan prestasi perniagaan.

\subsection{Persekitaran Luaran Persaingan Sengit}

Pembolehubah persekitaran luaran kedua yang akan dikaji dalam kajian ini adalah persaingan sengit. Menurut Covin et al. (1999) dan Lumpkin dan Dess (2001), persekitaran luaran persaingan sengit adalah berlawanan atau bertentangan dengan pembolehubah mesra perniagaan (munificence) termasuklah dari segi pengukurannya (Green, et al., 2008; Slevin \& Covin, 1997). Persaingan sengit merujuk kepada kesungguhan bersaing disebabkan kekurangan sumber-sumber (Davis, 2007) manakala persekitaran mesra lebih membantu firma dengan tahap kesediaan sumber-sumber yang dapat mengurangkan tahap risiko (Kreiser et al., 2002). Menurut Lumpkin dan Dess (2001), persekitaran persaingan sengit digunakan untuk mengambarkan tekanan luaran yang tidak menyokong dalam persekitaran sesebuah firma dalam pasaran atau industri yang diceburi.

Seterusnya, Miller dan Friesen (1978) mengambarkan persekitaran persaingan sengit sebagai persaingan terhadap harga, produk, teknologi, sekatan undang-undang yang ketat, kekurangan pekerja serta bahan mentah dan corak demografi yang tidak menguntungkan firma. Berdasarkan kajian awal tersebut, Miller dan Friesen (1983) telah merumuskan persekitaran persaingan sengit sebagai tahap ancaman yang dihadapi oleh firma disebabkan oleh pelbagai aspek serta tahap persaingan yang sangat sengit yang menyebabkan terjadinya turun naik firma dalam pasaran atau industri. Manakala Covin dan Slevin (1989) merujuk persekitaran luaran persaingan sengit sebagai suatu keadaan di mana wujudnya persaingan yang sangat sengit yang menyebabkan peluang firma untuk berjaya semakin berkurangan 
(Amran, 2006). Menurut Davis (2007), firma usahawan yang beroperasi dalam persekitaran persaingan sengit akan menyebabkan firma menjadi kurang kompetitif serta sentiasa berada dalam keadaan yang sangat berisiko seterusnya akan mempengaruhi prestasi firma.

Disebabkan keadaan tersebut maka faktor persekitaran persaingan sengit selalu dipertimbang untuk dikaji dan dibincangkan dalam kebanyakan literatur (Lumpkin, 1996; Lumpkin \& Dess, 1996). Contohnya kajian Davis (2007) mendapati firma keusahawanan lebih berjaya apabila beroperasi dalam persekitaran sengit. Dapatan tersebut turut disokong oleh kajian Becherer dan Maurer (1997) yang turut mendapati sikap orientasi keusahawanan berhubung secara positif apabila firma beroperasi dalam persekitaran sengit yang tinggi. Namun tidak semua kajian lepas mendapati persekitaran sengit berjaya meningkatkan hubungannya dengan prestasi firma (Amran, 2006). Menurut Davis (2007), terdapat juga kajian lepas yang mendapati persaingan sengit turut memberi impak negatif kepada prestasi firma disebabkan oleh sumber-sumber firma yang terhad. Maka, pengkaji telah mencadangkan hipotesis berikut untuk diuji;

Hipotesis 2: Persekitaran luaran persaingan sengit mempunyai hubungan yang signifikan dengan prestasi perniagaan.

\subsection{Persekitaran Luaran Mesra Perniagaan}

Seperti yang dibincangkan sebelum ini, persekitaran luaran mesra perniagaan mempunyai ciri-ciri yang bertentangan dengan persekitaran persaingan sengit (Slevin \& Covin, 1997; Covin et al., 1999; Lumpkin \& Dess, 2001; Green et al., 2008). Menurut Covin et al. (1999), persekitaran mesra perniagaan mempunyai ciri-ciri seperti kadar margin keuntungan yang tinggi, tahap persaingan yang rendah, tahap kesetiaan pelanggan yang tinggi dan dapat menerima sebarang pembuatan keputusan yang kurang baik oleh pihak pengurusan. Disebabkan ciri-ciri tersebut, maka kebanyakan kajian lepas mendapati kadar kegagalan firma yang beroperasi dalam persekitaran mesra perniagaan adalah rendah (Covin et al., 1999).

Didapati kebanyakan pengkaji lepas bersetuju bahawa persekitaran mesra perniagaan dikaitkan dengan tahap kesediaan sumbersumber kepada firma (Kreiser \& Davis, 2010; Davis, 2007; Kreiser et al., 2002; Lumpkin \& Dess, 2001; Zahra, 1993; Castrogiovanni, 1991). Menurut Castrogiovanni (1991: m/s. 552), persekitaran mesra perniagaan dapat diklasifikasikan kepada tiga dimensi utama iaitu;

i) kapasiti - merujuk kepada kesediaan sumber-sumber dalam persekitaran kepada firma keusahawanan.

ii) pertumbuhan atau kejatuhan - merujuk kepada kadar perubahan dalam kapasiti.

iii) peluang atau ancaman - merujuk kepada kadar kapasiti yang tidak dieksploitasi oleh firma.

Berdasarkan kepada tiga dimensi tersebut, Castrogiovanni (1991) merumuskan persekitaran mesra perniagaan sebagai sumbersumber utama yang diperlukan oleh firma atau pesaingnya untuk beroperasi semakin berkurangan atau melimpah dalam persekitaran tersebut. Manakala Zahra (1993) merujuk persekitaran mesra perniagaan sebagai ketersediaan sumber-sumber serta kewujudan peluangpeluang di dalam persekitaran luaran yang mesra perniagaan (Kreiser \& Davis, 2010; Kreiser et al., 2002). Menurut Davis (2007), ketersediaan sumber-sumber dalam persekitaran akan memberi kelebihan kepada firma untuk beroperasi serta memberi kesan yang positif kepada prestasi firma.

Didapati jumlah kajian lepas yang memeriksa pengaruh persekitaran luaran mesra perniagaan adalah terhad jika dibandingkan kajian ke atas persekitaran persaingan sengit. Walau bagaimanapun, kebanyakan pengkaji telah bersetuju bahawa persekitaran luaran mesra perniagaan mempunyai pengaruh yang kuat ke atas hubungannya dengan prestasi perniagaan (Lumpkin, 2006; Kreiser \& Davis, 2010; Rauch et al., 2009; Davis, 2007). Oleh itu, kajian ini berhasrat untuk menguji hipotesis berikut;

Hipotesis 3: Persekitaran luaran mesra perniagaan mempunyai hubungan yang signifikan dengan prestasi perniagaan.

\subsection{KERANGKA KONSEPTUAL}

Berdasarkan kepada ulasan literatur serta hipotesis yang dibangunkan, satu kerangka konseptual kajian dapat ditunjukkan seperti dalam Rajah 1.

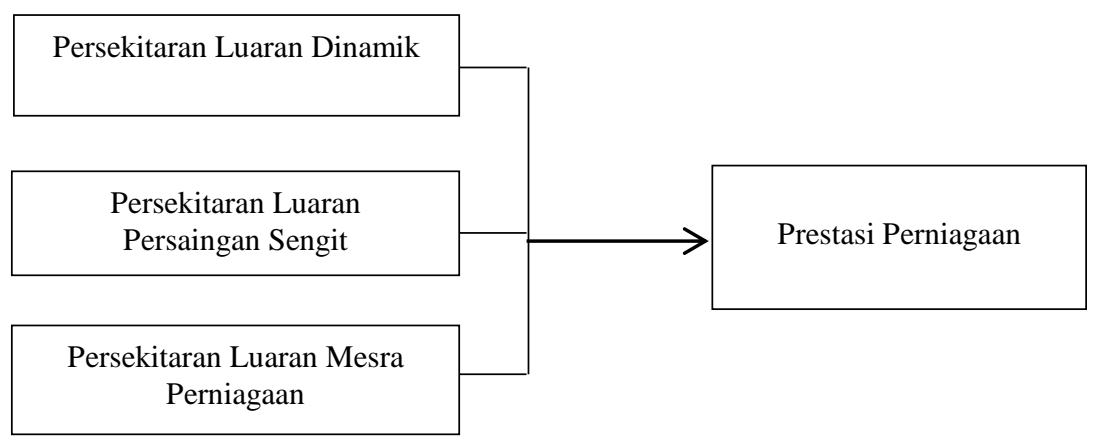

Rajah 1 Kerangka konseptual

Model dalam kajian ini menunjukkan keseluruhan cadangan kerangka untuk diperiksa dan dianalisis. Rajah 1 menunjukkan hubungan antara setiap pembolehubah persekitaran luaran (pembolehubah tidak bersandar) dengan prestasi perniagaan (pembolehubah bersandar). 


\subsection{METODOLOGI KAJIAN}

Responden bagi kajian ini terdiri daripada 7,187 buah firma perkilangan (termasuk asas tani) dan perkhidmatan berkaitan perkilangan yang beroperasi di Malaysia dan telah mendaftar dengan Perbadanan Perusahaan Kecil dan Sederhana Malaysia (SME Corp. Malaysia, 2009). Berdasarkan kepada jadual penentuan saiz sampel yang dihasilkan oleh Krejcie dan Morgan (1970), sampel saiz yang diperlukan dalam kajian ini adalah sebanyak 364. Selepas mengambil kira kadar jangkaan maklumbalas yang agak rendah di Malaysia, maka sebanyak 900 set borang soal selidik telah dipos kepada firma PKS yang dipilih. Pemilihan responden adalah berdasarkan kepada teknik persampelan rawak mudah. Daripada sejumlah 152 set soal selidik yang diterima, hanya 143 atau $11.92 \%$ set soal selidik yang telah digunakan selepas mengambilkira kes-kes outlier, borang tidak lengkap, dan diisi oleh responden yang tidak layak.

\subsection{Pengukuran Pembolehubah}

Pembolehubah persekitaran luaran dinamik telah diukur dengan menggunakan skala pengukuran yang diadaptasi daripada pengkaji dan sarjana lepas seperti Slevin dan Covin (1997) dan Green et al. (2008). Sebanyak lima item telah digunakan untuk mengukur persekitaran luaran dinamik. Seterusnya pembolehubah persekitaran luaran persaingan sengit dan mesra perniagaan telah diukur menggunakan enam item yang telah dibangunkan oleh Slevin dan Covin (1997) dan Green et al. (2008). Menurut Green et al. (2008), disebabkan oleh persekitaran persaingan sengit dan mesra perniagaan merupakan dua dimensi yang bertentangan antara satu sama lain, maka penggunaan item-item yang sama adalah diperlukan bagi membezakan situasi kedua-dua pembolehubah tersebut. Pengkaji perlu merujuk kepada skor min bagi mengetahui kecenderungan persekitaran luaran yang mana firma PKS di Malaysia beroperasi. Skor min yang tinggi bagi pengukuran tersebut merujuk kepada persekitaran persaingan sengit manakala skor min yang rendah lebih menjurus kepada persekitaran mesra perniagaan (Green et al., 2008). Format skala jenis Likert 7 mata telah digunakan bermula dengan 1 (sangat tidak bersetuju) hingga 7 (sangat setuju).

Pembolehubah prestasi perniagaan telah diukur dengan menggunakan lapan item berbentuk subjektif yang mengukur pertumbuhan perniagaan dan prestasi kewangan. Didapati kajian lepas telah membuktikan pendekatan pengukuran kewangan secara subjektif atau laporan sendiri adalah boleh dipercayai (Schulze et al., 2001). Item-item bagi prestasi perniagaan ini diukur dengan menggunakan teknik skala Likert 7 mata bermula dari nombor 1 (sangat rendah) hingga nombor 7 (sangat tinggi). Manakala skala nombor 4 merujuk kepada pemilihan prestasi yang sederhana bagi prestasi perniagaan sesebuah firma PKS. Responden diminta untuk menjawab kedudukan prestasi firma mereka berdasarkan kepada rekod tiga tahun lepas. Menurut Covin et al. (2001), purata rekod tiga tahun bertujuan untuk mengurangkan pengaruh variasi keputusan tahunan kewangan firma. Ia juga memadai bagi mengambarkan kedudukan semasa prestasi kewangan sesebuah firma PKS (Lumpkin, 1996).

\subsection{DAPATAN DAN PERBINCANGAN KAJIAN}

Merujuk kepada jadual 1, didapati majoriti responden yang terlibat dengan kajian ini terdiri dari negeri Kedah (19.6 peratus), di ikuti negeri Terengganu (13.3 peratus) dan negeri Selangor (11.2 peratus). Manakala responden dari negeri Perlis, Sabah dan Sarawak adalah yang paling rendah iaitu masing-masing sebanyak 2.1 peratus.

Hasil analisis mendapati kebanyakan firma PKS di Malaysia telah ditubuhkan antara 11 hingga 15 tahun (32.2 peratus), diikuti yang ditubuhkan antara 5 hingga 10 tahun (27.3 peratus). Seterusnya firma yang telah ditubuhkan antara 16 hingga 20 tahun (21.0 peratus) dan akhir sekali firma yang telah ditubuhkan lebih dari 20 tahun sebanyak 19.6 peratus. Keputusan analisis juga menunjukkan majoriti firma yang terlibat dalam kajian ini terdiri dari firma PKS bersaiz kecil (5 - 50 orang pekerja) sebanyak 63.6 peratus berbanding dengan firma PKS bersaiz sederhana (51 - 150 orang pekerja) sebanyak 36.4 peratus.

Jadual 1 Latar belakang firma PKS di Malaysia

\begin{tabular}{|c|c|c|}
\hline Kategori & Bil. Responden & Peratus (\%) \\
\hline \multicolumn{3}{|l|}{ Negeri } \\
\hline 1. Perlis & 3 & 2.1 \\
\hline 2. Kedah & 28 & 19.6 \\
\hline 3. Pulau Pinang & 11 & 7.7 \\
\hline 4. Perak & 9 & 6.3 \\
\hline 5. Kuala Lumpur & 8 & 5.6 \\
\hline 6. Selangor & 16 & 11.2 \\
\hline 7. Negeri Sembilan & 3 & 2.1 \\
\hline 8. Melaka & 11 & 7.7 \\
\hline 9. Johor & 13 & 9.1 \\
\hline 10. Pahang & 6 & 4.2 \\
\hline 11. Terengganu & 19 & 13.3 \\
\hline 12. Kelantan & 10 & 7.0 \\
\hline 13. Sabah & 3 & 2.1 \\
\hline 14. Sarawak & 3 & 2.1 \\
\hline \multicolumn{3}{|l|}{$\underline{\text { Tempoh Ditubuh }}$} \\
\hline 1. $5-10$ tahun & 39 & 27.3 \\
\hline 2. $11-15$ tahun & 46 & 32.2 \\
\hline 3. $16-20$ tahun & 30 & 21.0 \\
\hline 4. Lebih dari 20 tahun & 28 & 19.6 \\
\hline \multicolumn{3}{|l|}{ Bilangan Pekerja } \\
\hline 1. $5-50$ orang & 91 & 63.6 \\
\hline 2. $51-150$ orang & 52 & 36.4 \\
\hline
\end{tabular}




\begin{tabular}{llcc}
\hline \multicolumn{2}{l}{ Subsektor } & & \\
\hline 1. & Tekstil \& pakaian & 13 & 9.1 \\
2. $\quad$ Kayu \& perabot & 14 & 9.8 \\
3. $\quad$ Makanan \& minuman & 47 & 32.9 \\
4. $\quad$ Bahan kimia & 4 & 2.8 \\
5. $\quad$ Peralatan pengangkutan & 5 & 3.5 \\
6. $\quad$ Produk berasaskan logam & 16 & 11.2 \\
7. $\quad$ Elektrik \& elektronik & 11 & 7.7 \\
8. $\quad$ Getah \& plastik & 10 & 7.0 \\
9. Produk mineral bukan logam & 1 & 0.7 \\
10. & Peralatan mesin & 4 & 2.8 \\
11. Kertas \& pencetakan & 9 & 6.3 \\
12. & Kecantikan \& kesihatan & 9 & 6.3 \\
\hline
\end{tabular}

Bagi kajian ini, pengkaji telah mengkategorikan sektor perkilangan PKS kepada 12 subsektor utama berdasarkan kepada kepentingan setiap sektor seperti yang dicadangkan oleh SME Corp. Malaysia (2015). Keputusan kajian mendapati firma daripada subsektor makanan dan minuman adalah antara peratusan yang tertinggi iaitu sebanyak 32.9 peratus, manakala subsektor produk mineral bukan logam adalah antara yang terendah iaitu sebanyak 0.7 peratus. Bagi lain-lain subsektor yang terlibat dengan kajian ini dapat dirujuk dalam jadual 5.1.

Seterusnya berdasarkan kepada jadual 2, didapati pembolehubah persekitaran luaran dinamik telah menunjukkan skor min yang tertinggi (5.8692) diikuti dengan persaingan sengit (4.7083) dan mesra perniagaan (3.3301). Keputusan juga menunjukkan skor min bagi pembolehubah bersandar iaitu prestasi perniagaan adalah sebanyak 4.7173 yang juga boleh dianggap sebagai agak tinggi.

Jadual 2 Keputusan analisis deskriptif dan kolerasi Koefisien Pearson

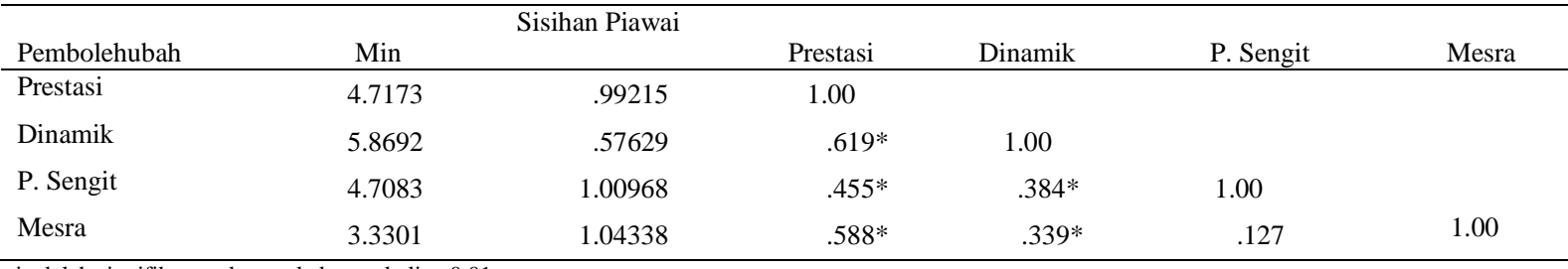

* Kolerasi adalah signifikan pada aras kebarangkalian 0.01

Analisis kolerasi koefisien Pearson telah dilakukan bagi menentukan arah dan kekuatan hubungan antara pembolehubah bersandar dengan setiap pembolehubah tidak bersandar (Pallant, 2007). Mengikut Cohen (1988), bagi pembolehubah yang mempunyi nilai $r$ lebih dari 0.50 boleh dianggap sebagai mempunyai hubungan kolerasi yang kuat. Keputusan kajian mendapati terdapat hubungan positif yang kuat antara pembolehubah persekitaran luaran dinamik $(r=0.619, p<.01)$ dan mesra perniagaan $(r=0.588, p<.01)$ dengan prestasi perniagaan. Manakala pembolehubah persekitaran luaran persaingan sengit $(r=0.455, p<.01)$ telah menunjukkan tahap kekuatan hubungan yang agak rendah tetapi berhubungan secara signifikan positif dengan prestasi perniagaan seperti yang ditunjukkan dalam Jadual 5.2.

Bagi hubungan antara setiap pembolehubah tidak bersandar didapati wujud hubungan yang bercampur-campur antara setiap hubungan tersebut. Keputusan kajian mendapati hubungan antara dinamik dengan persaingan sengit (0.384) dan dinamik dengan mesra perniagaan (0.339) adalah berkolerasi positif pada tahap yang agak rendah. Manakala hubungan antara mesra perniagaan dengan persaingan sengit adalah tidak singnifikan.

Analisis regresi berganda telah digunakan untuk menjawab ketiga-tiga hipotesis kajian. Jadual 3 menunjukkan keputusan analisis bagi analisis regresi berganda antara pembolehubah-pembolehubah persekitaran luaran dengan prestasi perniagaan.

Jadual 3 Keputusan regresi berganda antara setiap pembolehubah persekitaran luaran dengan prestasi perniagaan

\begin{tabular}{|c|c|c|c|c|c|}
\hline & \multicolumn{2}{|c|}{ Koefisien Tidak Terpiawai } & \multirow{2}{*}{$\begin{array}{c}\text { Koefisien Terpiawai } \\
\text { Beta }\end{array}$} & \multirow[b]{2}{*}{$t$} & \multirow[b]{2}{*}{ Sig. } \\
\hline & $\beta$ & Ralat Piawai & & & \\
\hline (Konstan) & -1.621 & .546 & & -2.971 & .003 \\
\hline Dinamik & .647 & .105 & .376 & 6.141 & $.000^{*}$ \\
\hline P. Sengit & .252 & .057 & .256 & 4.419 & $.000^{*}$ \\
\hline Mesra & .408 & .054 & .429 & 7.531 & $.000 *$ \\
\hline$R^{2}=0.601$ & \multicolumn{2}{|c|}{$R^{2}$ Terlaras $=0.593$} & Nilai $F=69.928$ & & \\
\hline
\end{tabular}

Keputusan menunjukkan koefisien regresi berganda untuk ketiga-tiga pembolehubah persekitaran luaran dengan prestasi perniagaan adalah $R=0.776$ dan $R^{2}=0.601$. Keputusan ini bermaksud ketiga-tiga pembolehubah persekitaran luaran (dinamik, persaingan sengit dan mesra perniagaan) yang dikaji dapat menerangkan 60.1 peratus variasi yang berlaku pada prestasi perniagaan. Didapati $R^{2}$ adalah signifikan dengan nilai $F=69.928$ dan nilai tahap signifikan pada $p<0.0001$. 
Merujuk kepada Jadual 5.3, keputusan kajian menunjukkan ketiga-tiga pembolehubah persekitaran luaran (dinamik, persaingan sengit dan mesra perniagaan) mempunyai hubungan yang signifikan ke atas prestasi perniagaan. Didapati pembolehubah persekitaran luaran dinamik mempunyai hubungan yang signifikan positif ke atas prestasi perniagaan $(\beta=0.376)$. Nilai $t=6.141$ dan nilai $p=0.000$ menunjukkan yang pembolehubah persekitaran luaran dinamik mempunyai hubungan yang signifikan dengan prestasi perniagaan pada $p<0.01$. Justeru, hipotesis 1 adalah disokong.

Didapati keputusan kajian ini selari dengan dapatan dari kajian Amran (2006), Covin dan Slevin (1989), Lumpkin dan Dess (2001), Zahra (1993) dan Miller dan Friesen (1983). Dapatan ini telah membuktikan firma PKS yang beroperasi di dalam persekitaran luaran dinamik berkeupayaan untuk meningkatkan prestasi perniagaan. Oleh itu dapatan ini juga telah menidakkan sebahagian hasil dapatan dari kajian Kreiser et al. (2002) dan Davis (2007) yang mendapati hubungan antara persekitaran luaran dinamik dengan prestasi perniagaan adalah tidak signifikan.

Seterusnya keputusan analisis juga mendapati pembolehubah persekitaran luaran persaingan sengit mempunyai hubungan yang signifikan positif ke atas prestasi perniagaan $(\beta=0.256)$. Nilai $t=4.419$ dan nilai $p=0.000$ menunjukkan yang pembolehubah persekitaran luaran persaingan sengit mempunyai hubungan yang signifikan dengan prestasi perniagaan pada $p<0.01$. Maka, hipotesis 2 adalah disokong. Dapatan turut membuktikan firma PKS berupaya untuk meningkatkan prestasi perniagaan mereka walaupun beroperasi pada persekitaran yang bersaing dengan sengit. Keputusan kajian ini selari dengan hasil dapatan oleh Lumpkin (1996) dan Becherer dan Maurer (1997) yang turut bersetuju firma yang beroperasi dalam persekitaran persaingan sengit mampu meningkatkan prestasi perniagaan.

Keputusan kajian turut mendapati pembolehubah persekitaran luaran mesra perniagaan mempunyai hubungan yang signifikan positif dengan prestasi perniagaan $(\beta=0.429)$. Nilai $t=7.531$ dan nilai $p=0.000$ menunjukkan yang pembolehubah persekitaran luaran mesra perniagaan mempunyai hubungan yang signifikan dengan prestasi perniagaan pada $p<0.01$. Maka, hipotesis 3 adalah disokong. Hubungan yang signifikan ini selari dengan kenyataan pengkaji-pengkaji lepas seperti Lumpkin (2006), Kreiser dan Davis (2010), Rauch et al. (2009) dan Davis (2007) yang turut bersetuju bahawa persekitaran luaran mesra perniagaan mempunyai pengaruh yang kuat ke atas hubungannya dengan prestasi perniagaan.

\section{ם.0 KESIMPULAN DAN IMPLIKASI}

Kajian yang dijalankan secara empirikal ini cuba mencari jawapan tentang hubungan di antara setiap pembolehubah persekitaran luaran (dinamik, persaingan sengit dan mesra perniagaan) dengan prestasi perniagaan firma PKS di Malaysia. Didapati hasil kajian ini telah mengesahkan ketiga-tiga pembolehubah persekitaran luaran (dinamik, persaingan sengit dan mesra perniagaan) mempunyai hubungan yang signifikan positif dengan prestasi perniagaan selari dengan kajian Lumpkin dan Dess (1996), Davis (2007), Miller dan Friesen (1983) dan Kreiser dan Davis (2010).

Seterusnya menurut Zikmund (2000), dengan menganalisis magnitiud koefisien, pembolehubah yang mempunyai nilai mutlak (beta terpiawai) yang terbesar (dengan mengabaikan tanda positif atau negatif) adalah mempunyai penerangan variasi atau pengaruh yang terbesar terhadap pembolehubah bersandar. Oleh itu, dengan mengambil kira pembolehubah-pembolehubah lain sebagai konstan, didapati pembolehubah persekitaran luaran mesra perniagaan merupakan pembolehubah penerang atau pengaruh yang besar dengan nilai beta terpiawai sebanyak 0.429 berbanding dengan pembolehubah persaingan sengit dan dinamik. Dapatan ini menunjukkan firma PKS di Malaysia memilih untuk beroperasi di dalam persekitaran yang lebih mesra perniagaan bagi meningkatkan prestasi semasa perniagaan mereka. Keputusan ini berbeza dengan beberapa kajian lepas yang mendapati firma lebih cenderung untuk beroperasi dalam persekitaran luaran sengit berbanding persekitaran mesra perniagaan (Green et al., 2008; Lumpkin \& Dess, 2001; Slevin \& Covin, 1997).

Walaupun hubungan antara pembolehubah persekitaran persaingan sengit dengan prestasi perniagaan menunjukkan hubungan yang signifikan positif, tetapi didapati nilai beta terpiawainya $(\beta=0.256)$ adalah yang terendah. Nilai yang rendah ini mungkin memberi petunjuk bahawa firma PKS di Malaysia berada dalam situasi yang sangat berisiko, di mana kesilapan dalam membuat keputusan akan mengancam firma dan seterusnya menyebabkan kadar kegagalan firma dalam industri yang diceburi adalah tinggi. Faktor lain yang menyebabkan prestasi firma berada pada tahap yang rendah adalah kemungkinan disebabkan oleh kadar persaingan domestik dan antarabangsa yang sengit, tahap kesetiaan pelanggan yang rendah, perang harga yang terlalu sengit dan margin keuntungan yang sangat rendah. Keadaan ini akan menyebabkan firma PKS berada dalam keadaan yang sentiasa terancam. Kesannya, firma PKS yang beroperasi dalam persekitaran luaran persaingan sengit ini berkemungkinan akan menghadapi tahap prestasi yang rendah. Maka disarankan agar firma keusahawanan yang beroperasi di dalam persekitaran yang bersaing sengit ini perlulah sentiasa memantau serta merebut peluang melalui penekanan kepada tindakan yang berinovatif dan proaktif bagi memastikan firma terus bersaing dalam persekitaran luaran yang tidak menentu.

Hasil kajian turut mendapati firma PKS yang beroperasi di dalam persekitaran dinamik juga perlu berhati-hati bagi memastikan prestasi perniagaan mereka tidak terjejas. Jika dirujuk kepada beta terpiawainya $(\beta=0.376)$, didapati nilai ini memberi petunjuk bahawa firma PKS di Malaysia berada dalam situasi yang baik. Walau bagaimanapun firma PKS harus memantau persekitaran semasa bagi memastikan firma dapat mempertahankan prestasi perniagaan mereka. Firma PKS di Malaysia perlu memahami dan sentiasa meramal tindakan dari pesaing yang selalu berubah-ubah serta sukar untuk meramal kehendak dan permintaan dari pelanggan yang pelbagai. Firma juga harus bersedia untuk menghadapi tekanan dari faktor ekonomi, teknologi, sosial dan politik yang berkemungkinan akan menyebabkan pasaran menjadi tidak stabil akibat dari perubahan yang drastik ini. Justeru itu, firma PKS di Malaysia mesti berhati-hati apabila beroperasi di dalam persekitaran yang tidak menentu ini.

Didapati semua hasil dapatan kajian ini telah memberi implikasi dan sumbangan penting kepada kajian mengenai pengaruh persekitaran luaran ke atas firma PKS di Malaysia. Pihak pengurusan tertinggi firma PKS perlu memastikan ketiga-tiga persekitaran (dinamik, persaingan sengit dan mesra perniagaan) sentiasa dipantau agar dapat terus bersaing selari dengan perkembangan semasa. Seterusnya pihak kerajaan serta agensinya perlulah menyediakan bantuan dan khidmat nasihat kepada firma PKS bagi membuat persediakan kepada elemen yang dibincangkan di atas.

Dari sudut akademik, kajian pada masa hadapan harus mengambil kira faktor luaran serta dalaman firma yang berkemungkinan akan turut mempengaruhi prestasi firma. Kajian ke atas strategi keusahawanan, sumber-sumber firma dan peranan pihak kerajaan perlulah diambil kira untuk kajian pada masa hadapan. Seterusnya kajian pada masa hadapan juga mesti mengambil kira pengukuran prestasi 
perniagaan secara multidimensi seperti yang disarankan oleh Kreiser et al. (2002). Pengukuran boleh dilakukan dengan memeriksa sumbangan yang unik antara setiap pembolehubah pertumbuhan perniagaan dan tingkat keuntungan secara berasingan (Wiklund \& Shepherd, 2005).

\section{Rujukan}

Alkali, M. (2012). Assessing the Influence of External Environmental Factors, on the Performance of Small Business Manufacturing enterprises in Bauchi state, Nigeria. Interdisciplinary Journal of Contemporary Research in Business, 4(7), 621-628.

Amran, A. (2006). Orientasi Keusahawanan Firma Dan Prestasi Perusahaan Kecil Dan Sederhana (PKS) Bumiputera: Kajian Impak Penyederhana Beberapa Faktor Persekitaran Yang Ditanggap. Tesis PhD yang tidak diterbitkan, Universiti Sains Malaysia.

Azizi Halipah. (2010). Pengaruh Kompetensi Keusahawanan, Struktur Organisasi Dan Persekitaran Terhadap Prestasi Perusahan Kecil Dan Sederhana Di Malaysia. Tesis PhD yang tidak diterbitkan, Universiti Utara Malaysia.

Becherer, R. C. \& Maurer, J. G. (1997). The moderating effect of environmental variables on the entrepreneurial and marketing orientation of entrepreneur-led firms Entrepreneurship Theory and Practice, 22(1), 47-58.

Castrogiovanni, G. J. (1991). Environmental Munificence: A Theoretical Assessment. Academy of Management Review, 16(3), 542-565.

Covin, J. G. \& Slevin, D. P. 1989. Strategic Management Of Small Firms In Hostile And Benign Environments. Strategic Management Journal, 10: 75-87.

Covin, J. G. \& Slevin, D. P. (1991). A Conceptual Entrepreneurship As Firm Behavior. Entrepreneurship Theory and Practice, 16(1), 7-25.

Covin, J. G. \& Slevin, D. P. (1998). Adherence To Plans, Risk Taking, And Environment As Predictors Of Firm Growth. The Journal of High Technology Management Research, 9(2), 207-237.

Covin, J. G., Slevin, D. P. \& Heeley, M. B. (1999). Pioneers And Followers: Competitive Tactics, Environment, And Firm Growth. Journal of Business Venturing, 15, $175-210$.

Covin, J. G., Slevin, D. P. \& Heeley, M. B. (2001). Strategic Decision Making In An Intuitive Vs. Technocratic Mode: Structural And Environmental Considerations. Journal of Business Research, 52(1), 51-67.

Davis, J. L. (2007). Firm-Level Entrepreneurship And Performance: An Examination And Extension Of Relationships And Measurements Of The Entrepreneurial Orientation Construct. Unpublished doctoral dissertation, The University of Texas at Arlington.

Dess, G. G., \& Beard, D. W. (1984). Dimensions Of Organizational Task Environments. Administrative Science Quarterly, 17, 313-327.

Donaldson, L. (2001). The Contingency Theory Of Organizations. Thousand Oaks, CA: Sage Publications.

Green, K. M., Covin, J. G. \& Slevin, D. P. (2008). Exploring The Relationship Between Strategic Reactiveness And Entrepreneurial Orientation: The Role Of Structure-Style Fit. Journal of Business Venturing, 23(3), 356-383.

International Monetary Fund (IMF). (2015). Diperolehi dari http://www.imf.org/ external/index.htm

Kreiser, P. M. \& Davis, J. (2010). Entrepreneurial Orientation And Firm Performance: The Unique Impact Of Innovationess, Proactiveness And Risk-Taking. Journal of Small Business and entrepreneurship, 23(1), 39-51.

Kreiser, P. M., Marino, L. W. \& Weaver, K. M. (2002). Assessing the relationship Between Entrepreneurial Orientation, The External Environment, And Firm Performance in Frontiers of Entrepreneurship Research. Wellesley, MA: Babson College 199-208.

Krejcie, R. V. \& Morgan, D. W. (1970). Determining Sample Size For Research Activities. Educational and Psychological Measurement, 30, 607-610.

Lumpkin, G. T. (1996). The Entrepreneurial Orientation (EO) Of New Entrants: Performance Implication Of Alternative Configuration Of EO, Environment, And Structure. Unpublished Doctoral Dissertation, The University of Texas at Arlington.

Lumpkin, G. T. \& Dess, G. (1996). Clarifying the Entrepreneurial Orientation Construct And Linking It To Performance. Academic Management Review, 21(1), 135172.

Lumpkin, G. T. \& Dess, G. G. (2001). Linking Two Dimensions Of Entrepreneurial Orientation To Firm Performance: The Moderating Role Of Environment And Industry Life Cycle. Journal of Business Venturing, 16, 429-451.

Madrid-Guijarro, A., Auken, H.V. \& Garcia, D. (2007). An Analysis Of Factors Impacting Performance Of Spanish Manufacturing Firms. Journal of Small Business and Entrepreneurship, 20(4), 369-386.

Miller, D. \& Friesen, P. (1978). Archetypes of Strategy Formulation. Management Science, 24, 921-933.

Miller, D. \& Friesen, P. H. (1983). Strategy-Making And Environment: The Third Link. Strategic Management Journal, 4, 221-235.

Mohd Khairuddin, H. (2002). Small dan Medium-Sized Enterprises In Malaysia: Development Issues / Mohd Khairuddin Hashim, Syed Azizi Wafa. Petaling Jaya: Prentice Hall.

Normah Mohd Aris. (2007). SMEs: Building Blocks for Economic Growth. Journal of the Department of Statistics, Malaysia, 1, 1-14.

Pallant, J. (2007). SPSS Survival Manual: A Step By Step Guide To Data Analysis Using SPSS For Windows (Version 15). (3 $3^{\text {rd }}$ ed.). Crows Nest, NSW: Allen \& Unwin.

Pasanen, M. (2003). In Search Of Factors Affecting SME Performance: The Case Of Eastern Finland. Unpublished Doctoral Dissertation, University of Kuopio.

Rauch, A., Wiklund, J., Lumpkin, G. T. \& Frese, M. (2009). Entrepreneurial Orientation And Business Performance: An Assessment Of Past Research And Suggestions For The Future. Entrepreneurship Theory and Practice, 33(3), 761-787.

Robbins, S. P. \& Coulter, M. (2007). Management ( $9^{\text {th }}$ ed.). Upper Saddle River, New Jersey: Pearson Prentice-Hall.

Schulze, W. S., Lubatkin, M. H., Dino, R. N. \& Buchholtz, A. K. (2001). Agency Relationships In Family Firms: Theory And Evidence. Organization Science, 12(2), 99-116.

Slevin, D. P. \& Covin, J. G. (1997). Strategy Formation Patterns, Performance, And The Significance Of Context. Journal of Management, 23(2), $189-209$.

SME Corp. Malaysia. (2009). Majlis Pembangunan PKS Kebangsaan: Laporan Tahunan PKS 2008. Diperolehi dari http://www.smidec.gov.my/ms/node/766

SME Corp. Malaysia. (2015). Diperolehi dari http://www.smecorp.gov.my/index.php/en/

SME Corp. Malaysia. (2016). Diperolehi dari http://www.smecorp.gov.my/index.php/en/resources/2015-12-21-11-07-06/asean-publication

SMIDEC. (2006). SME Performance Report 2005. Petaling Jaya: SMIDEC.

The World Bank. (2015). Diperolehi dari http://www.worldbank.org/

Wiklund, J. \& Shepherd, D. (2005). Entrepreneurial Orientation And Small Business Performance: A Configurational Approach. Journal of Business Venturing, 20(1), $71-91$.

Yang, C-W. (2006). The Effect Of Leadership And Entrepreneurship Orientation Of Small And Medium Enterprises On Business Performance in Taiwan. Unpublished doctoral dissertation, University of the Incarnate Word.

Zahra, S. A. (1993). Environment, Corporate Entrepreneurship And Financial Performance: A Taxonomic Approach. Journal of Business Venturing, 8, 319-340. 